\title{
Investigating the Shading Impact of Rail on the Energy Output of a PV System in Hong Kong
}

\author{
Jinqing Peng ${ }^{a, b}$, Lin $\mathrm{Lu}^{b, *}$, Hongxing Yang ${ }^{b}$, Tao Ma ${ }^{b}, \mathrm{KM} \mathrm{HO}^{c}$, Peter Law \\ ${ }^{a}$ College of Civil Engineering, Hunan University, Changsha 410082, Hunan, China \\ ${ }^{b}$ Renewable Energy Research Group (RERG), Department of Building Services Engineering, \\ The Hong Kong Polytechnic University, Hong Kong, China \\ ${ }^{c}$ Water Supplies Department (WSD), Hong Kong, China
}

\begin{abstract}
This paper investigates the shading impact of rail on the power performance of a PV system. In order to find out the reasons of energy loss, an on-site inspection and testing was conducted. The shading and aging problems were found in the process of visual inspection. The shading problem can be further subdivided into edge-shading, pillar-shading and nameplate shading. To further understand and quantify the impact of different types of shadings on the power output performance, the I-V curves of a $P V$ module were tested under different solar radiation. The testing results showed that the impact of different types of shadings on the power performance varied with the Sun position, solar radiation as well as the time. In general, the edgeshading effect reduced the energy output of $P V$ system by $11 \%-15 \%$, the pillar-shading effect reduced the energy output by $15 \%-19 \%$, and both effects of edge-shading and pillar-shading reduced the energy output of $P V$ system by $18 \%-35 \%$. Thus, the main reason that resulted in the energy loss of this $P V$ system was attributed to the shading impact. If the edge-shading and pillar-shading problems are solved, the annual energy output of the PV system could increase about $20 \%-24 \%$.
\end{abstract}

\section{Introduction}

The photovoltaic (PV) system diagnosed in this study is located in Pak Kong water treatment works (PKWTW) in Hong Kong. This PV system was built in 2007. It is facing southwest and with a tilted angle of about $20^{\circ}$. The total PV installation capacity is about $10.6 \mathrm{kWp}$, comprising by 60 pieces of monoSi PV modules. Recently, the customers reflected that the PV system is always operating under a low energy conversion efficiency state, thus an on-site testing and diagnosing work has been done to find out the problems. It was found that the actual average annual energy output was $9396 \mathrm{kWh}$, which is lower than the theoretical annual energy output by $23 \%$, and lower than the PV system with current PV technology ( $17 \%$ efficiency) by $57 \%$. Thus the purpose of this study is to find out the reasons causing the $23 \%$ energy loss. The PV arrays of this PV system are shown in Figure 1. These PV modules purchased from three different manufacturers, viz. Suntech, Shell and Solgro, and were divided into 6 PV arrays. The specification parameters of the PV modules are listed in Table 1. In each array, 10 pieces of the same modules were connected in series. Every two arrays, whose PV modules came from the same manufacturer, were connected in parallel before connected into an Inverter. Three SMC 6000A inverters manufactured by SMA were used in this system to inverter the DC power to AC power. Figure 2 shows the picture of the SMC 6000A inverter. The specification parameters of the inverters are listed in Table 2. The schematic diagram of the PV system is presented in Figure 3. From the specifications of the PV modules and Inverters, there is no mismatching problem between the PV modules and inverters.

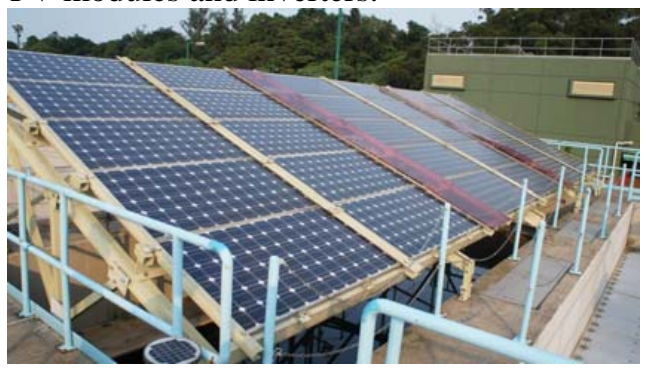

Figure 1. The PV arrays of the PV system (only half arrays were shown in this photo)

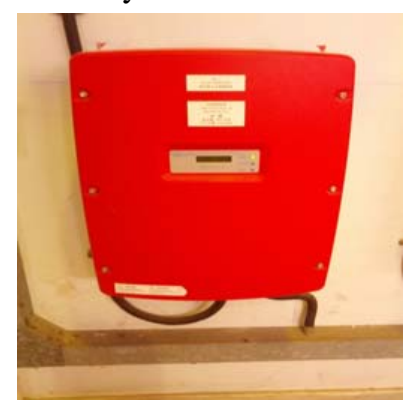

Figure 2. The photo of the SMC 6000A inverter (three this kind of inverters were used in this system) 
Table 1. Specification parameters of the mono-Si PV modules

\begin{tabular}{|l|l|l|l|}
\hline Parameters/manufacturers & Shell & Suntech & Solgro \\
\hline Maximum Power at STC $\left(\mathrm{P}_{\max }\right)$ & $175 \mathrm{~W}$ & $175 \mathrm{~W}$ & $180 \mathrm{~W}$ \\
\hline Optimum Operating Voltage $\left(\mathrm{V}_{\mathrm{mp}}\right)$ & $35.4 \mathrm{~V}$ & $35.2 \mathrm{~V}$ & $35.2 \mathrm{~V}$ \\
\hline Optimum Operating Current $\left(\mathrm{I}_{\mathrm{mp}}\right)$ & $4.95 \mathrm{~A}$ & $4.95 \mathrm{~A}$ & $5.11 \mathrm{~A}$ \\
\hline Open Circuit Voltage $\left(\mathrm{V}_{\mathrm{oc}}\right)$ & $44.6 \mathrm{~V}$ & $44.2 \mathrm{~V}$ & $43.6 \mathrm{~V}$ \\
\hline Short Circuit Current $\left(\mathrm{I}_{\mathrm{sc}}\right)$ & $5.43 \mathrm{~A}$ & $5.2 \mathrm{~A}$ & $5.5 \mathrm{~A}$ \\
\hline Module Efficiency & $13.3 \%$ & $13.7 \%$ & $14 \%$ \\
\hline No. of PV modules/PV arrays & $20 / 2$ & $20 / 2$ & $20 / 2$ \\
\hline Dimensions & $1622 \times 814 \times 40 \mathrm{~mm}$ & $1580 \times 808 \times 35 \mathrm{~mm}$ & $1580 \times 808 \times 35 \mathrm{~mm}$ \\
\hline
\end{tabular}

Table 2. Specification parameters of the SMC 6000A inverter

\begin{tabular}{|l|l|}
\hline Parameters & values \\
\hline Max. operating voltage (DC) & $600 \mathrm{~V}$ \\
\hline Operating voltage range (DC) & $213-600 \mathrm{~V}$ \\
\hline Nominal operating voltage (DC) & $270 \mathrm{~V}$ \\
\hline Max. input current (DC) & $26 \mathrm{~A}$ \\
\hline Nominal operating voltage (AC) & $230 \mathrm{~V}$ \\
\hline Nominal operating frequency (AC) & $50 / 60 \mathrm{~Hz}$ \\
\hline Nominal output power (AC) & $6000 \mathrm{~W}$ \\
\hline Max. output power (AC) & $6000 \mathrm{~W}$ \\
\hline Max. output current (AC) & $26 \mathrm{~A}$ \\
\hline
\end{tabular}

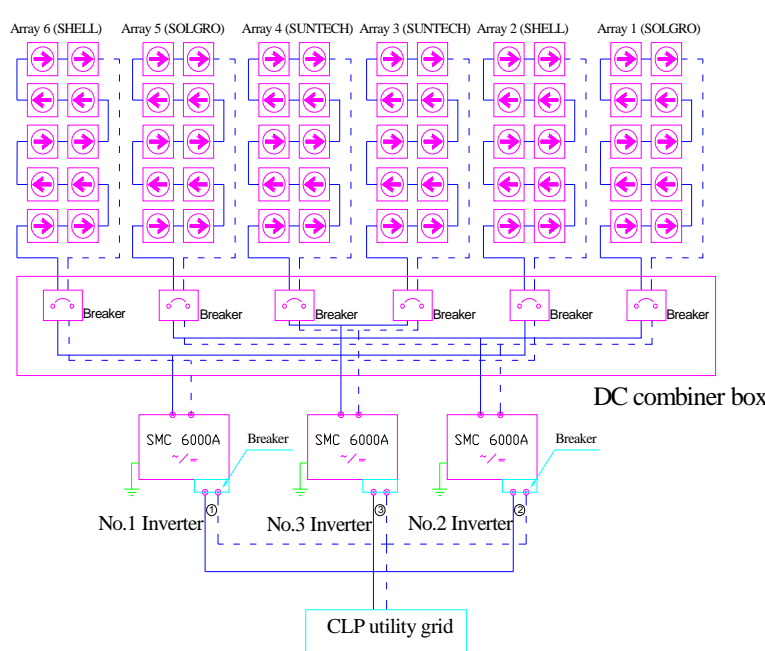

Figure 3. Schematic diagram of the PV system

\section{Analyzing of energy loss}

The theoretical annual energy output of this PV system can be calculated by (1):

$$
E_{\text {theoretical }}=A_{\text {act. }} \times G \times \eta_{\text {stc }} \times \lambda
$$

Where, $E_{\text {theoretical }}$ is the theoretical annual energy output, (kWh); $A_{\text {act. }}$ is the active area of the all PV modules, $\left(\mathrm{m}^{2}\right)$, the total active area is about $77.4 \mathrm{~m}^{2}$; $\eta_{\text {stc }}$ is the PV modules' energy conversion efficiency under standard test conditions (STC). According to the specifications of PV manufacturers, the energy conversion efficiency of the above mentioned three kinds of PV modules are respectively $13.3 \%$ for Schell, $13.7 \%$ for Suntech and $14 \%$ for Solgro. $\lambda$ is the performance ratio of PV system. This ratio considers all losses from converting solar energy into direct current electricity and then inverting the direct current into alternating current electricity. In this study, $\lambda$ is assumed to be 0.75 [1]. $G$ is the annual total solar radiation received by the $\mathrm{PV}$ modules, (kWh/yr.) The horizontal hourly solar radiation was recorded by a sun tracker with two pyranometers in the Hong Kong Polytechnic University. However, only horizontal total and diffuse solar radiations can be recorded by this equipment. Thus, it is necessary to transfer the total solar radiation on a horizontal surface into the incident solar radiation on the sloping surface of PV modules. The hourly total solar radiation incidence on a tilted surface, $G_{t t}$ $\left(\mathrm{W} / \mathrm{m}^{2}\right)$, can be expressed as follows:

$$
G_{\mathrm{tt}}=G_{b t}+G_{d t}+G_{r}
$$

Where, $G_{b t}$ is the hourly beam solar radiation incidence on a tilted surface, $\mathrm{W} / \mathrm{m}^{2}$; $\mathrm{G}_{\mathrm{dt}}$ is the hourly diffuse solar radiation incidence on a tilted surface, $\mathrm{W} / \mathrm{m}^{2}$; and $\mathrm{G}_{\mathrm{r}}$ is the hourly reflected solar radiation, $\mathrm{W} / \mathrm{m}^{2}$.

The ratio of beam radiation on the tilted surface to that on a horizontal surface can be defined as geometric factor of $\mathrm{R}_{\mathrm{b}}$, which is given in the equation (3). Therefore if we get the beam radiation on the horizontal surface, the beam radiation on the tilted surface can be easily calculated by the equation (4) [2].

$$
\begin{gathered}
R_{b}=\frac{G_{b t}}{G_{b h}}=\frac{\cos \theta}{\cos \theta_{z}} \\
G_{b t}=G_{b h} \times R_{b}=G_{b h} \times \frac{\cos \theta}{\cos \theta_{z}}
\end{gathered}
$$

Where $G_{b h}$ is the beam radiation on the horizontal surface which can be extracted from the total radiation of $\mathrm{G}_{\text {th }}$ on the horizontal surface (provided by Hong Kong Observatory); $\theta$ is the angle of incidence, i.e. the angle between the beam radiation on a surface and the normal to that surface; $\theta_{z}$ is the zenith angle, i.e. the angle between the vertical and the line to the sun. 
In order to calculate the reflected term, it is assumed that all the surrounding surfaces are condensed into one large horizontal diffusely reflecting ground. The radiation reflected from this composite "ground" contributes to the reflected component. The inclined surface with $\beta$ degree to the horizontal has a view factor of $(1-\cos \beta) / 2$ to the ground. If the ground has a reflectance of $\rho_{o}$ for the total solar radiation, the reflected radiation from the ground, Gr, can be written as:

$$
G_{r}=\frac{\rho_{o}}{2} \cdot G_{t h} \cdot(1-\cos \beta)
$$

Where $\mathrm{G}_{\text {th }}$ is the total irradiance on a horizontal surface, which can directly obtain from the Hong Kong Observatory; $\rho_{o}$ is the ground reflectance which is equal to 0.2 for normal ground and may range from 0.35 to 0.95 for ground covered by snow.

Although there are a lot of models, such as Liu \& Jordan Model, Hay \& Davies Model, Perez Model and Reindl Model [3], can be used to simulate the diffuse solar irradiance on tilted surface, it is also the most difficult part to be simulated and a relatively big error may be generated if the choosing model is not suitable for the local weather condition. Lu [4] compared various diffuse models in different tilted angles at five orientations (south, southeast, southwest, east and west) using a typical meteorological year (TMY) weather data in Hong Kong. Results showed that for PV modules with a lower tilted angle, Perez model provides results with high accuracy after validation using Hong Kong weather data. Thus, in this study, the Perez model [56] was chosen to simulate the diffuse radiation on tilted surface. This model considered the circumsolar and horizon brightening. In addition, it derived the reduced brightness coefficients which are functions of the sky clearness, $\varepsilon$ and sky brightness, $\Delta$ to account for the isotropic diffuse radiation. The diffuse on the tilted surface is given by following equation [5-6]:

$$
G_{d t}=G_{d h} \cdot\left[\left(1-F_{1}\right) \cdot\left(\frac{1+\cos \beta}{2}\right)+F_{1} \cdot \frac{a}{b}+F_{2} \cdot \sin \beta\right]
$$

Where $G_{d h}$ is the diffuse radiation on the horizontal surface which can be extracted from the total radiation on the horizontal, $\mathrm{G}_{\mathrm{th}}$;

Where $a=\max [0, \cos \theta]$,

$b=\max \left[\cos 85, \cos \theta_{z}\right]$,

$F_{1}=F_{11}(\varepsilon)+F_{12}(\varepsilon) \cdot \Delta+F_{13}(\varepsilon) \cdot \theta_{Z}$

$F_{2}=F_{21}(\varepsilon)+F_{22}(\varepsilon) \cdot \Delta+F_{23}(\varepsilon) \cdot \theta_{Z}$
The values of $F_{11}, F_{12}, F_{13}, F_{21}, F_{22}$, and $F_{23}$ can be found from the tables given by Perez et al [5]. The value of $\varepsilon$ and $\Delta$ can be calculated as follows:

$$
\begin{gathered}
\varepsilon=\frac{\left[\left(G_{d h}+G_{b n}\right) / G_{d h}+1.041 \theta_{z}^{3}\right]}{\left[1+1.041 \theta_{z}^{3}\right]} \\
\Delta=\frac{G_{d h} \cdot m}{G_{o n}}=\frac{G_{d h} \cdot m}{G_{o} / \cos \theta_{z}}=\frac{G_{d h}}{G_{o}}
\end{gathered}
$$

Where $\theta_{z}$ is in radian; $\mathrm{m}$ is the air mass.

In order to simulate the annual solar radiation received by the PV modules, a FORTRAN program was developed based on the above mathematic models. Figure 4 presents the simulated annual solar radiation incident on different tilted surface. It was found that the average annual solar radiation received by the PV modules installed with 20 degree tilted is about $1340 \mathrm{kWh}$, which is a little less than the highest solar radiation received by the optimum orientation and tilted angle. In Hong Kong, the optimum orientation for PV installation is south facing with 22 degree tilted. In addition, it is also found that the average diffuse solar irradiance on tilted surface is higher than the average beam irradiance by $90 \mathrm{kWh} / \mathrm{m}^{2} / \mathrm{yr}$., which means that the diffuse solar irradiance would contribute to more PV power output. Substituting the solar radiation G, energy conversion efficiency $\eta_{s t c}$, performance ratio

$\lambda$, and active area $A_{\text {act. }}$ into equation (1), the theoretical energy output was calculated to be 11700 $\mathrm{kWh} /$ year. The actual energy output of this PV system was recorded from June 2007 to June 2013. Figure 5 presents the monthly energy output of this PV system. Figure 6 shows the annual energy output from 2008 to 2012. It is found that the actual average annual energy output was $9396 \mathrm{kWh}$, which is lower than the theoretical annual energy output by $24.5 \%$. Thus the purpose of this study is to find out the reasons causing the $24.5 \%$ energy loss.

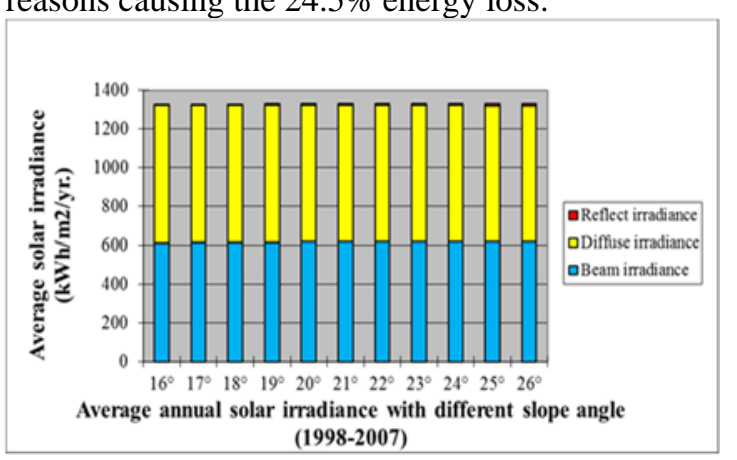

Figure 4. The simulated diffuse and beam irradiance incident on different tilted surfaces 


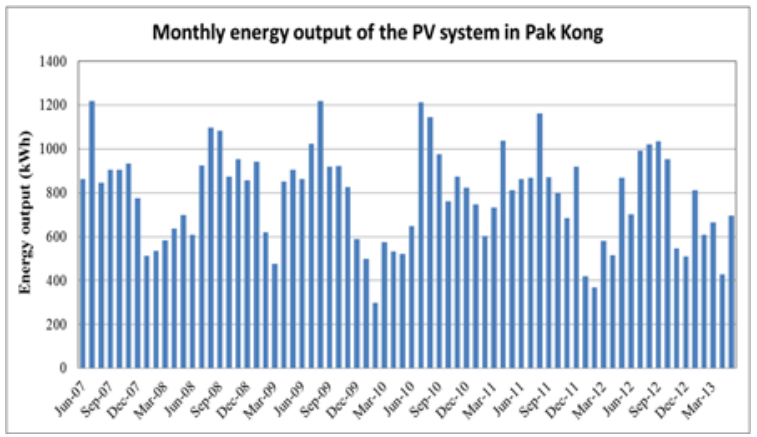

Figure 5. Monthly energy output of the PV system

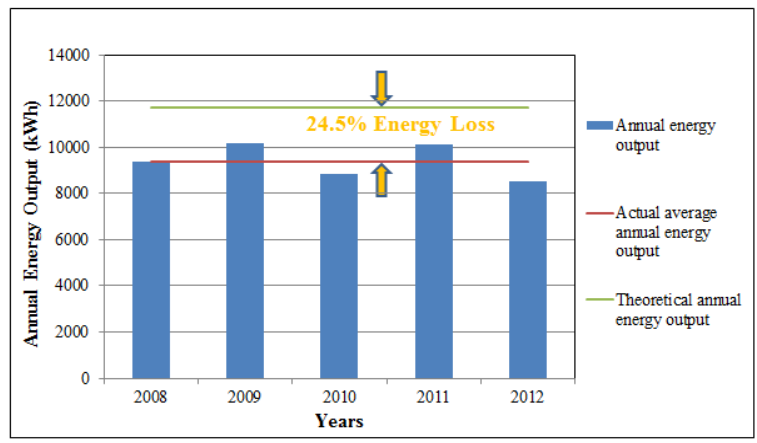

Figure 6. Annual energy output and the average energy loss of the PV system

\section{Inspecting and Testing}

\subsection{Visual inspection}

Three problems were found in the process of visual inspection. First of all, two kinds of permanent shading were found to affect the power output performance of PV system, viz. edge-shading caused by the U-bar and the pillar-shading caused by the pillars in front of the PV modules. Figure 7 shows the edge-shading caused by the U-bar. Almost all PV modules, except the PV modules manufactured by Shell, are affected by the edge-shading. Figure 8 shows the comparison of edge-shading effect on Shell's PV module and Suntech's PV module. It can be seen that there is almost no edge-shading for the Shell's PV module due to its longer length (1622 $\mathrm{mm}$ ) than the other two types of PV modules. And this is the reason why the inverter connected to the PV modules made by Shell has higher average electricity production rate. The hourly average electricity production rate of the Shell's PV arrays is about $0.81 \mathrm{kWh}$, while they are 0.65 and $0.71 \mathrm{kWh}$ for the PV arrays made by Solgro and Suntech, respectively. Thus, from the average electricity production rate, it is found that only the edgeshading could reduce the energy output of the PV modules by about $12 \%$.

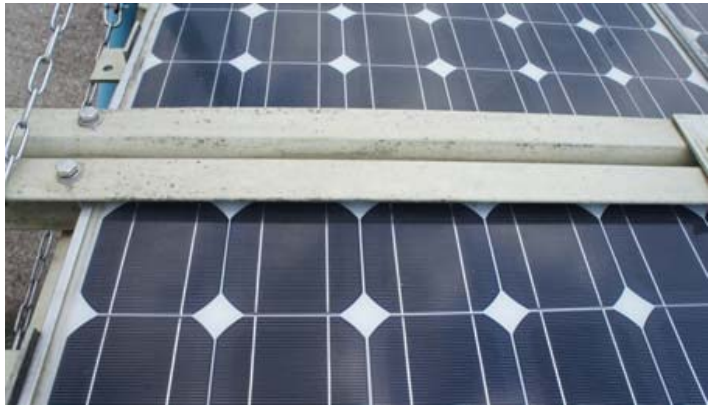

Figure 7. Edge-shading caused by the U-bar

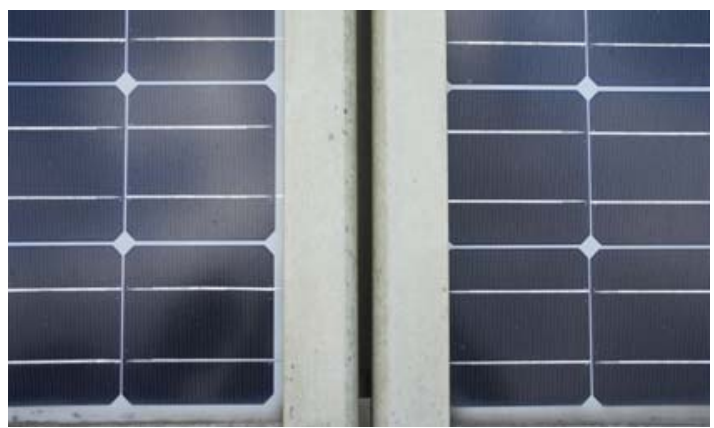

Figure 8. Comparison of the edge-shading effect on the Shell's PV module (left one) and the Suntech's PV module (right one)

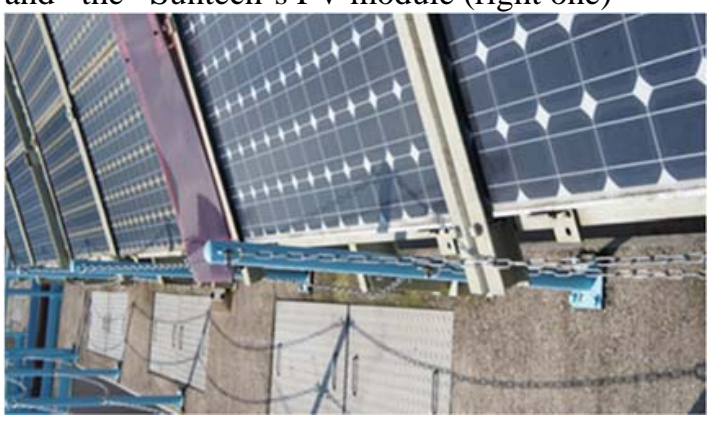

Figure 9. the pillar-shading caused by the pillars in front of the PV modules.

Figure 9 shows the pillar-shading caused by the pillars in front of the PV modules. It can be seen that almost all the PV modules in the first row were shaded by the pillars. Secondly, a temporary shading caused by a nameplate was found and showed in Figure 10. This kind of shading may cause the energy output performance of the PV array reducing significantly.

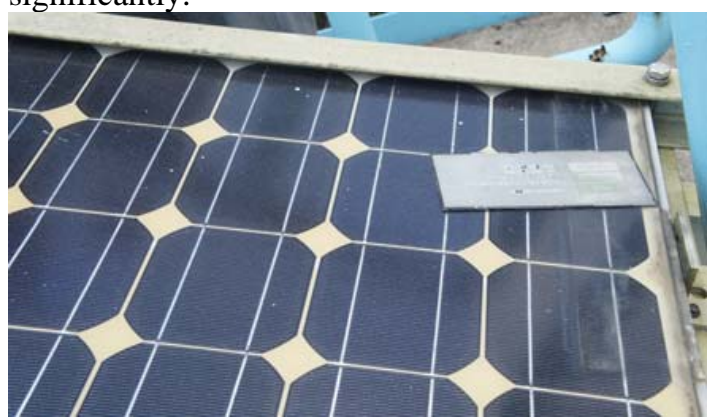

Figure 10. A temporary shading caused by a nameplate 
Last but not least, it was fond that there are some quality problems for the PV modules made by Solgro. Firstly, a few pieces of multi-Si solar cells exist in the mono-Si PV panels, as shown in Figure 11. Secondly, as shown in Figure 12, the aging problem is very serious and the EVA of the PV modules has become yellow. Thus it can be seen that the PV modules made by Solgro have quality problems on the solar cells and EVA. And this is the reason why the inverter connected to the PV modules made by Solgro has the lowest average electricity production rate of $0.65 \mathrm{kWh}$, even its rated power is higher than the PV modules made by the other two manufacturers.

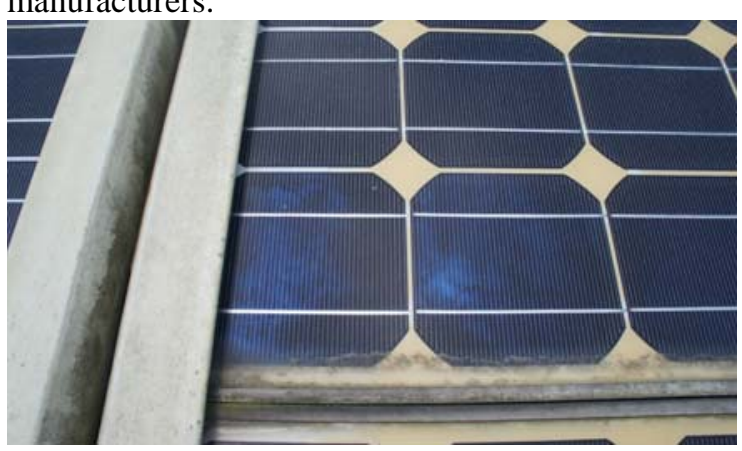

Figure 11. A few pieces of multi-Si solar cells were found in the mono-Si PV panels

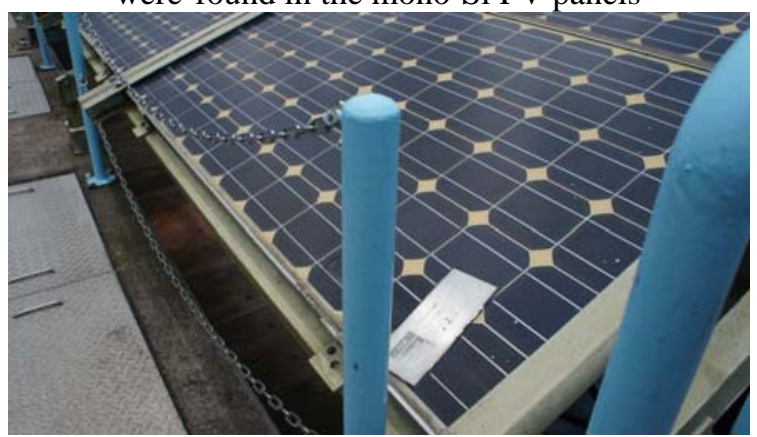

Figure 12. The aging problem is very serious and the EVA of the PV modules has become yellow

\subsection{I-V measuring and power testing}

In order to further understand and quantify the impact of different types of shadings on the power output performance, a PV module made by Suntech was disassembled for conducting I-V testing.

Figure 13 presents the $\mathrm{I}-\mathrm{V}$ testing results under different shading conditions at 12:51-12:56. It can be seen that the maximum power is about $146 \mathrm{~W}$ without shading, but it was reduced to $126 \mathrm{~W}$ affected by edge-shading, to $118 \mathrm{~W}$ affected by pillar-shading, and further reduced to $110 \mathrm{~W}$ affected by both edgeshading and pillar-shading. The edge-shading resulted in the reduction of open circuit voltage and short circuit current, and reduced the power output by about $14 \%$. The pillar-shading caused the reduction of the maximum power of PV module and reduced the power output by about $19 \%$. Both the effects of edge-shading and pillar-shading reduced the power output by about $25 \%$.

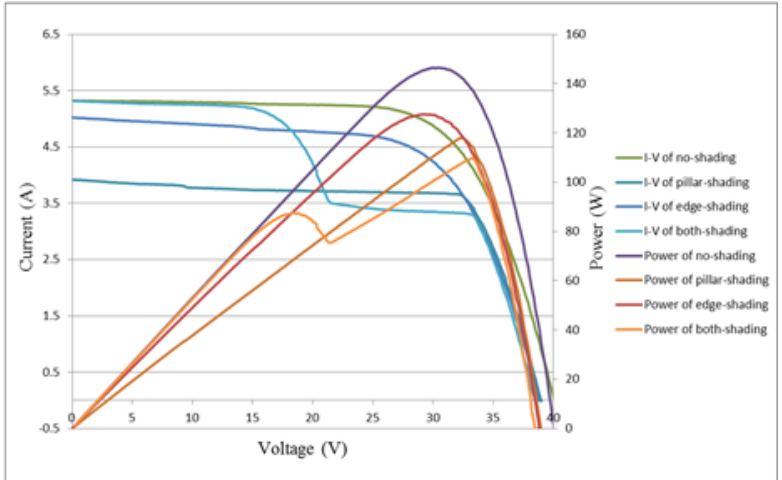

Figure 13. I-V testing results under different shading conditions at 12:51-12:56

Figure 14 presents the I-V testing results under different shading conditions at 14:11-14:23. It can be seen that the maximum power is about $122 \mathrm{~W}$ without shading, but it was reduced to $103 \mathrm{~W}$ affected by edge-shading, to $102 \mathrm{~W}$ affected by pillar-shading, and further reduced to 93W affected by both edgeshading and pillar-shading. The edge-shading effect reduced the power output by about $15 \%$. The pillarshading effect caused the reduction of the maximum power of PV module and reduced the power output by about $16 \%$. Both the effects of edge-shading and pillar-shading reduced the power output by about $24 \%$.

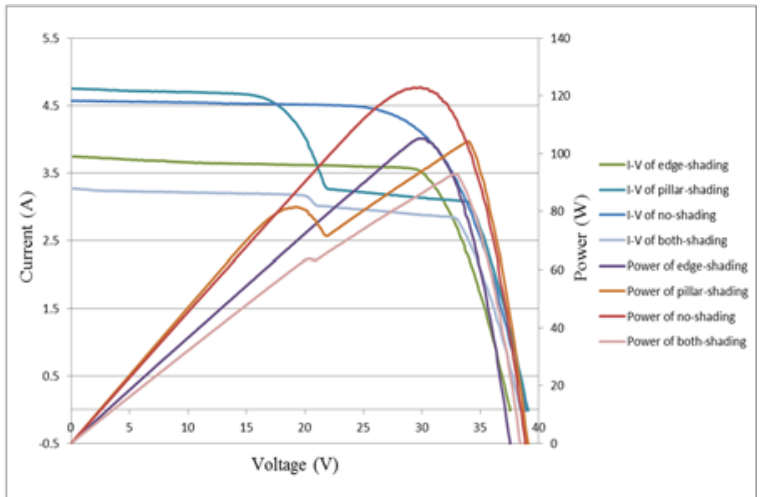

Figure 14. I-V testing results under

different shading conditions at 14:11-14:23

Figure 15 presents the I-V testing results under different shading conditions at 15:17-15:19. It can be seen that the maximum power is about $111 \mathrm{~W}$ without shading, but it was reduced to $96 \mathrm{~W}$ affected by edge-shading, to $94 \mathrm{~W}$ affected by pillar-shading, and further reduced to $91 \mathrm{~W}$ affected by both the effects of edge-shading and pillar-shading. The edgeshading effect reduced the power output by about $14 \%$. The pillar-shading effect caused the reduction of the maximum power of PV module and reduced the power output by about $15 \%$. Both the effects of edge-shading and pillar-shading reduced the power output by about $18 \%$. 


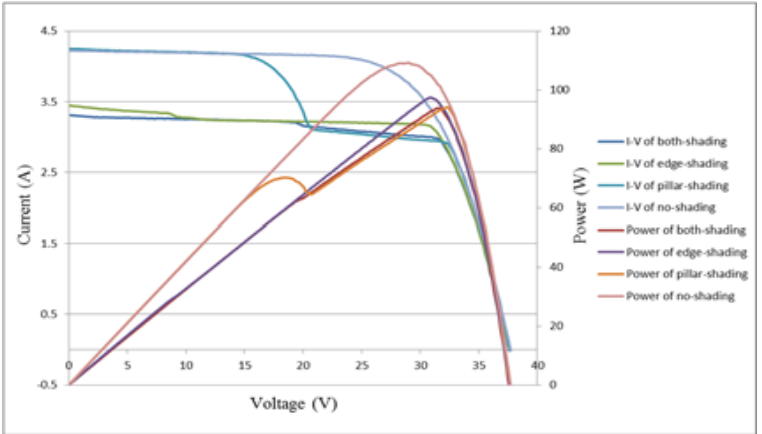

Figure 15. I-V testing results under different shading conditions at 15:17-15:19

Figure 16 presents the I-V testing results under different shading conditions at 16:11-16:13. It can be seen that the maximum power is about $90 \mathrm{~W}$ without shading, but it was reduced to $80 \mathrm{~W}$ affected by edgeshading, to 73W affected by pillar-shading, and further reduced to $59 \mathrm{~W}$ affected by both edgeshading and pillar-shading. The edge-shading effect reduced the power output by about $11.1 \%$. The pillar-shading effect caused the reduction of the maximum power of PV module and reduced the power output by about 19\%. Both the effects of edge-shading and pillar-shading reduced the power output by about $35 \%$.

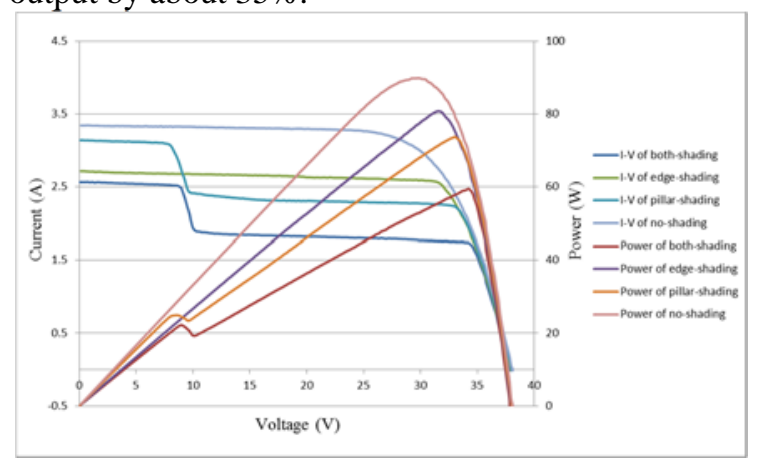

Figure 16. I-V testing results under different shading conditions at 16:11-16:13

\section{Suggestion}

Based on the above analysis, some suggestions are proposed to solve these problems and improve the PV system's energy output.

(1) As shown in Figure 17, removing or cutting down the pillars in front of the PV modules to completely avoid the pillar-shading. Actually, the pillar-shading has worse effect on the energy output of PV system than the edge-shading.

(2) As shown in Figure 18, readjusting the position of the U-bar to reduce the edgeshading. This is the easiest way to reduce the effect of edge-shading on the energy output, but it may not completely avoid this shading effect. Thus other installation way should be developed to replace the existing installation way to completely solve the edge-shading problem.

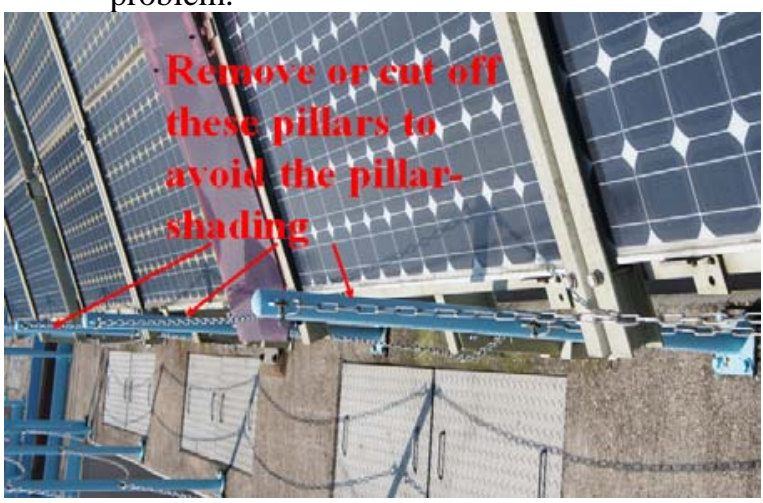

Figure 17. Removing or cutting down the pillars in front of the PV modules to completely avoid the pillar-shading

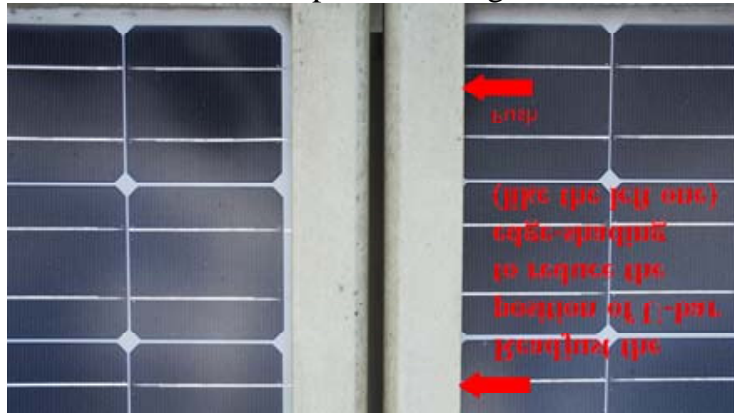

Figure 18 Readjusting the position of U-bar to reduce the edge-shading effect

\section{Discussion and Conclusions}

Based on the above testing results, it was found that the impact of different types of shadings varied with the Sun position, solar radiation as well as the time. In general, on $20^{\text {th }}$ June 2013, the edge-shading effect reduced the energy output of PV system by $11 \%-15 \%$, the pillar-shading effect reduced the energy output by $15 \%-19 \%$, and both effects of edge-shading and pillar-shading reduced the energy output of PV system by $18 \%-35 \%$. It is worth noting that the shading effect varies with the Sun position, it may cause much more energy loss in winter than in summer due to the increase of shading area.

In addition, the inverters' energy output data was recorded. The inverter, which was connected to the PV modules made by Solgro, generated about 10.5 $\mathrm{kWh}$ on June 20, but the inverter connected to the PV modules made by Shell generated about12.6 $\mathrm{kWh}$, which is higher than that of Solgro's PV modules by $20 \%$. There are two reasons may explain why the energy output performance of Solgro's PV modules was lower than that of Shell's. On the one hand, the power performance of Solgro's PV modules was decayed due to the aging problem. On the other hand, the edge-shading also reduced the power output of Solgro's PV modules.

Ideally, the inverters connected to the PV modules made by Shell and Solgro should generate 
about $14 \mathrm{kWh}$ on June 20 based on the solar radiation and PV modules' temperature. Thus the energy loss caused by the shading effect was about 1.4 kWh for the Shell's PV modules, which is accounted for $10 \%$ of the ideal energy output. These results agree well with the I-V testing results which were mentioned above. The energy loss for the Solgro's PV modules was about $3.5 \mathrm{kWh}$, which is account for $25 \%$ of the ideal energy output. This energy loss was mainly caused by the both effects of edge-shading and pillar-shading, as well as the PV modules' performance degradation.

In a word, it can be concluded that the main reasons causing the energy loss of the PV system are the shading problems. If the edge-shading and pillarshading problems are solved, the annual energy output of the PV system could increase about $20 \%$ $24 \%$.

\section{Acknowledgements}

The authors appreciate the financial supports provided by the Water Supplies Department (WSD) of the Hong Kong Special Administrative Region (HKSAR).

\section{References}

[1] J. Peng, L. Lu, "Investigation on the development potential of rooftop PV system in Hong Kong and its environmental benefits," Renewable and Sustainable Energy Reviews, vol.

27, pp. 149-162, November 2013.

[2] J. A. Duffie, WA. Beckman, Solar engineering of thermal processes, (Third Edition). John Wiley \& Sons, INC., New York, 2006.

[3] Li Danny HW, Cheung Gary HW. Study of models for predicting the diffuse irradiance on inclined surfaces. Appl Energy 2005;81(2):170-86.

[4] Lu L. Investigation on characteristics and application of hybrid solar-wind power generation systems. Ph.D. dissertation, The Hong Kong Polytechnic University; 2004.

[5] R. Perez, P. Ineichen, R. Seals, Modeling of daylight availability and irradiance components from direct and global irradiance, Solar Energy, vol. 44(5), pp. 271-289, 1990.

[6] R. Perez, R. Seals, P. Ineichen, R. Stewart, D. Menicucci, A new simplified version of the Perez diffuse irradiance model for tilted surfaces, Solar Energy, vol. 39(3), pp. 221-231, 1987. 